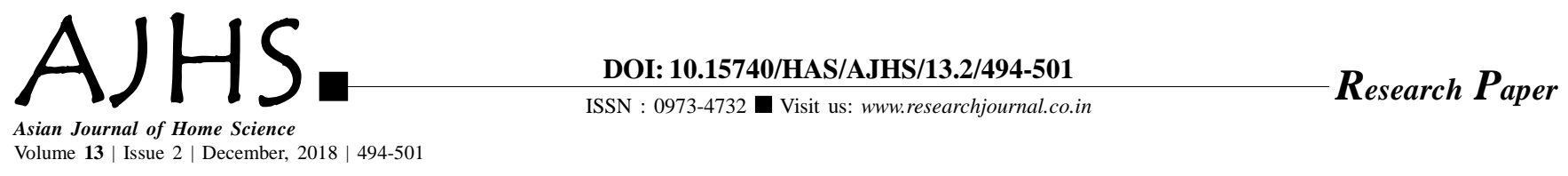

\title{
Self-regulation and metacognitive skillfulness among adolescents
}

\author{
Parvinder Kaur, Sarita Saini and Deepika Vig
}

Received: 05.03.2018; Revised: 10.10.2018; Accepted: 23.10.2018

See end of the paper for authors' affiliations Parvinder Kaur Department of Human Development and Family Studies, College of Home Science, Punjab Agricultural University, Ludhiana (Punjab) India

Email : pkparvinder8@ gmail.com
ABSTRACT : The present study aims to investigate the relationship between varying dimensions of self-regulation and the two components of metacognition. Metacognition and self-regulation should be explored as a serious issue in the educational context as both aim at helping learners to think about their own learning more explicitly. The sample for this study comprised 400 adolescents studying in class +1 and +2 , exclusively drawn from the Government Senior Secondary Schools of rural and urban areas of Ludhiana and Moga districts of Punjab. The subjects were randomly selected and equally distributed over gender (males=200 and females $=200$ ) and locale (urban=200 and rural $=200$ ). Metacognitive Awareness Inventory (Schraw and Dennison, 1994) and Self-Regulation Questionnaire (Brown et al., 1999) were used to assessthe metacognition and self-regulation of adolescents, respectively. Irrespective of gender and locale, the results of Pearson Correlation analysis revealed a significant positive correlation between overall self-regulation and the components of metacognition (Knowledge about Cognition and Regulation of Cognition) as well as overall metacognition. Similar results were also observed in case of female respondents as well as the rural respondents, where a significant positive correlation was found between self-regulation and metacognition.

KEY WORDS: Adolescents, Metacognition, Self-regulation

- HOW TO CITE THIS PAPER : Kaur, Parvinder, Saini, Sarita and Vig, Deepika (2018). Self-regulation and metacognitive skillfulness among adolescents. Asian J. Home Sci., 13 (2) : 494-501, DOI: 10.15740/ HAS/AJHS/13.2/494-501. Copyright@ 2018: Hind Agri-Horticultural Society. 